\title{
Studi Literatur: Analisis Permasalahan Pembelajaran Kimia SMA Pada Materi Stoikiometri
}

\author{
Listia Fauziyyah Ahmad \\ Postgraduate Student of Chemistry Education Departemen Universitas Pendidikan Indonesia, \\ Setiabudi No.229, Isola, Kota Bandung 40154 \\ Listiafauziyyahahmad@upi.edu
}

ARTICLE HISTORY

Revised: 14 February 2022

Accepted: 24 February 2022

\begin{abstract}
ABSTRAK
Problematika miskonsepsi dan kesulitan siswa dalam memecahkan masalah numerik pada topik stoikiometri masih terjadi. Sebagian besar fokus penelitian hanya ditujukan pada cara mengungkap miskonsepsi siswa, padahal mengidentifikasi penyebab dan memberi solusi untuk mengatasi hal tersebut tidak kalah pentingnya. Kesulitan dalam stoikiometri disebabkan kurangnya pemahaman konsep mol, ketidakmampuan menyetarakan persamaan kimia, penggunaan hubungan stoikiometri yang tidak konsisten, mengidentifikasi pereaksi pembatas, penentuan hasil teoritis, dan identifikasi zat yang berlebihan. Pendidik perlu menganalisis serta menerapkan teknik pedagogis sebagai sarana untuk mengatasi miskonsepsi dan kesulitan siswa dalam memecahkan masalah numerik diantaranya memperbaiki prakonsepsi siswa, pembelajaran dengan model student centered learning, membuat peta konsep dan mind map, berlatih memecahkan soal dengan langkah-langkah algoritmik dan melakukan pembelajaran yang mencapai tingkat ketuntasan. Karena keberhasilan siswa dalam memahami materi stoikometri menjadi faktor penentu dalam mempelajari materi selanjutnya yang memerlukan konsep stoikiometri sebagai materi prasyarat.
\end{abstract}

Kata kunci: stoikiometri, miskonsepi, kesulitan belajar, kompetensi pedagogik, pemecahan masalah

\section{ABSTRACT}

Students' misconceptions and difficulties in solving numerical problems on the topic of stoichiometry still occur until now. Most of the research focus is aimed at uncovering students' misconceptions, whereas identifying the causes and providing solutions to overcome them is no less important. Deficiencies in stoichiometry are caused by a lack of understanding of the mole concept, inability to balance chemical equations, inconsistent stoichiometric relationships, determining the limiting reagent, producing theoretical results, and excesses. Educators need to analyze and apply pedagogical techniques as a means to overcome students' misconceptions and difficulties in solving their problems improving students' preconceptions, learning with student-centered learning models, making concept and mind maps, practicing problem solving with algorithmic steps and learning which reaches the level of completeness. Because the success of students in understanding stoichiometric factors is a determinant in studying further material that requires the concept of stoichiometry as a prerequisite for the material.

Keywords : stoichiometry, misconceptions, learning difficulties, pedagogic competence, problem solving

\section{Pendahuluan}

Sebagian besar ilmu kimia dibangun oleh konsep-konsep abstrak seperti lambang unsur dan molekul, teori atom dan ikatan kimia. Salah satu konsep yang diperlukan sebagai materi kimia dasar adalah stoikiometri. Stoikiometri merupakan salah satu topik awal dalam peta sekuensi topik-topik Kimia SMA dan materi bab terakhir pada semester genap kelas X dalam Kurikulum 2013. Konsep stoikiometri merupakan jembatan untuk mempelajari dan memahami konsep kimia lainnya (Winarni, dkk., 2013; Noorarniea, dkk., 2019). Materi ini mencakup persamaan reaksi sederhana, penerapan hukum kekekalan massa, hukum Gay Lussac, Avogadro, dan perhitungan dasar kimia (Chang, 2010). Sehingga siswa membutuhkan pemahaman konsep lebih, agar mengalami kesulitan dalam mempelajari materi lainnya. (Shadreck dan Enunuwe, 2017).

Stoikiometri masih dianggap sulit karena siswa harus memadukan konsep dengan perhitungan matematika juga memerlukan kemampuan analisis dalam menyelesaikan soal-soalnya. Kesukaran ini berimbas pada kualitas proses dan hasil pembelajaran jika siswa tidak memahami konsep atau memiliki miskonsepsi (Setyorini, dkk., 2018). Perbedaan kemampuan siswa dalam menerima dan memahami konsep dengan konsep ilmiah yang sebenarnya sesuai para ahli kimia dapat dikatakan 
miskonsepsi yang terjadi akibat dari kesalahan dalam menalar atau kelebihan dan kekurangan dalam menganalisis konsep (Astuti dkk, 2016). Persisten miskonsepsi menjadi sumber keraguan saat bertemu dengan konsep yang saling berikatan sehingga mempengaruhi pemahaman siswa untuk materi selanjutnya (Shui-Te et al., 2018). Beberapa faktor yang dapat menyebabkan miskonsepsi pada siswa diantaranya situasi yang kurang kondusif, kurangnya ketertarikan siswa terhadap pembelajaran kimia, cara belajar yang kurang benar, kurangnya keberanian untuk bertanya, motivasi belajar siswa yang rendah (Ayu, dkk.,2021).

Problematika miskonsepsi dan kesulitan siswa dalam memecahkan masalah pada topik stoikiometri masih terjadi meskipun studi tentang identifikasi miskonsepsi sudah banyak dilakukan beberapa diantaranya peneliti Indonesia (Aini dkk, 2017; Astuti dkk, 2016; Damayanti, 2017). Namun, sebagian besar fokus penelitian tersebut hanya ditujukan pada cara mengungkap miskonsepsi siswa, padahal mengidentifikasi penyebab miskonsepsi serta mencari strategi atau solusi untuk mengatasi miskonsepsi dan kesulitan tersebut tidak kalah pentingnya. Maka dari itu, identifikasi kecenderungan miskonsepsi yang dialami oleh siswa perlu diketahui agar menjadi dasar mencari solusi dan strategi pembelajaran yang tepat. Dengan demikian, dapat ditentukan implikasi yang tepat terhadap proses pembelajaran di sekolah sehingga dapat menghindari miskonsepsi siswa pada materi stoikiometri dan tidak menghambat terhadap pemahaman konsep kimia lain sehingga mengurangi kesulitan siswa dalam belajar materi stoikiometri.

Kompetensi pedagogik guru sebagai pendidik memiliki peran yang penting dalam kegiatan belajar mengajar yaitu merupakan kemampuan guru dalam pengelolaan pembelajaran siswa. Menurut Zamania (2008), kompetensi pedagogik tersebut meliputi: 1) Kemampuan dalam memahami karakteristik perkembangan siswa, seperti memahami tingkat kognitif siswa sesuai dengan usianya; 2) Kemampuan dalam membuat perancangan pembelajaran; 3) Kemampuan melaksanakan pembelajaran yang mendidik dan dialogis; 4) kemampuan dalam mengevaluasi hasil belajar mampu merancang dan melaksanakan penilaian dan melaksanakan evaluasi. Adapun upaya yang dapat dilakukan pendidik yaitu dengan menggunakan teknik pedagogis pemecahan masalah sebagai sarana untuk mengatasi kesulitan siswa dalam pemecahan masalah stoikiometri (Shadreck, 2018), strategi yang digunakan saat pembelajaran baik itu metode, teknik, serta penggunaan bahan ajar yang menyajikan konten secara sederhana, logis dan koheren sehingga dapat meminimalkan terjadinya miskonsepsi dan kesulitan belajar siswa dalam materi stoikiometri.

\section{Metode}

Metode yang digunakan dalam penulisan artikel ini yaitu studi literature review mengenai berbagai problematika pembelajaran kimia pada materi stoikiometri serta sampai kepada bagaimana mengatasi problematika tersebut. Literature review pada artikel ini terdiri dari beberapa tahap yaitu pencarian informasi dari artikel hasil penelitian relevan terkait stoikiometri yang telah dipublikasikn baik pada jurnal nasional maupun internasional, tahap selanjutnya yaitu analisis dan sintesis literatur yang berkaitan. Hasil dari studi literatur ini dianalisis dan disimpulkan menjadi sebuah temuan yang berupa gagasan mengenai problematika pembelajaran kimia pada topik stoikiometri serta solusi untuk mengatasinya. Sehingga hasil akhir dari kajian pustaka ini akan memberikan deskripsi terkait pembelajaran yang dapat diterapkan oleh guru pada materi stoikiometri untuk mengatasi problematika tersebut.

\section{Hasil dan Pembahasan \\ Jenis-Jenis Miskonsepsi Siswa}

Perbedaan kemampuan siswa dalam memahami konsep yang sebenarnya sesuai para ahli kimia disebut miskonsepsi yang terjadi akibat dari kesalahan dalam menalar atau kelebihan dan 
kekurangan dalam menganalisis konsep (Astuti dkk, 2016). Persisten miskonsepsi menjadi sumber keraguan saat bertemu dengan konsep yang saling berikatan sehingga mempengaruhi pemahaman siswa untuk materi selanjutnya (Shui-Te et al., 2018). Beberapa miskonsepsi mengenai materi stoikiometri yang ditemukan oleh penelitian sebelumnya yaitu Sidauruk (2005) dan Astuti dkk (2016) dengan Diagnostik Stoikiometri (TDS) berjenis pilihan ganda two-tier, Aini dkk (2017) mengidentifikasi miskonsepsi menggunakan instrumen three-tier dan metode Certainty of Response Index (CRI) termodifikasi oleh Damayanti (2017).

Tabel 1. Miskonsepsi Siswa pada Topik Stoiliometri

Label Konsep Miskonsepsi

\begin{tabular}{ll}
\hline Massa Atom Relatif (Ar) & Ar suatu unsur disamakan dengan massa satu atom unsur \\
dan Massa Molekul Relatif & tersebut dalam gram (Sudarmo, 2013) \\
(Mr) &
\end{tabular}

Persamaan Reaksi Jumlah molekul sebelum dan sesudah reaksi adalah sama menganggap bahwa mol adalah sama dengan molekul (Purba, 2007)

Jumlah koefisien reaksi sebelum dan sesudah reaksi selalu sama pada suatu persamaan reaksi, yang disetarakan adalah jumlah koefisiennya(Astuti dkk., 2016 ; Damayanti, 2017)

Volume dianggap merepresentasikan massa pada persamaan reaksi gas, sehingga volume sebelum dan sesudah reaksi adalah sama. (Wiwianan dkk., 2020)

\begin{tabular}{|c|c|}
\hline \multirow[t]{3}{*}{ Hukum Dasar Kimia } & $\begin{array}{l}\text { Reaksi yang menghasilkan gas pada sistem tertutup, massa } \\
\text { setelah reaksi menjadi lebih besar (Purba, 2007) }\end{array}$ \\
\hline & $\begin{array}{l}\text { Pada suhu dan tekanan yang sama, volume total sebelum reaksi } \\
\text { sama dengan volume total (Purba, 2007) }\end{array}$ \\
\hline & $\begin{array}{l}\text { Gas-gas yang diukur pada suhu, tekanan, dan volume yang } \\
\text { sama memiliki jumlah molekul yang berbeda, karena masing- } \\
\text { masing gas mempunyai massa molar yang berbeda-beda } \\
\text { (Purba, 2007) }\end{array}$ \\
\hline \multirow[t]{2}{*}{ Konsep Mol } & $\begin{array}{l}\text { Bila molekul yang berbeda mempunyai jumlah mol yang sama, } \\
\text { maka jumlah atom penyusun molekul tersebut selalu sama } \\
\text { (Astuti dkk., 2016) }\end{array}$ \\
\hline & $\begin{array}{l}\text { rumus } \mathrm{V}=\mathrm{n} \times 22,4 \mathrm{~L} \text { digunakan untuk mengerjakan soal } \\
\text { algoritmik mengenai senyawa berwujud gas meskipun tidak } \\
\text { berlangsung dalam keadaan standar (Sidaruk, } 2005 \text {; Anugrah, } \\
\text { 2019) }\end{array}$ \\
\hline \multirow[t]{2}{*}{ Stoikiometri Reaksi } & $\begin{array}{l}\text { Semua reaktan habis bereaksi tanpa mempertimbangkan } \\
\text { adanya pereaksi pembatas (Anugrah, 2019) }\end{array}$ \\
\hline & $\begin{array}{l}\text { pereaksi pembatas adalah pereaksi yang massanya paling kecil, } \\
\text { pereaksi pembatas adalah senyawa yang mempunyai koefisien }\end{array}$ \\
\hline
\end{tabular}


terkecil, dan pereaksi pembatas sama dengan pereaksi yang mempunyai jumlah mol terkecil (Anugrah, 2019)

Perbandingan koefisien menunjukkan perbandingan semua satuan yang terlibat dalam suatu reaksi, khususnya massa zat

Tidak melibatkan koefisien saat menghitung mol suatu zat dari mol zat lain yang diketahui dalam reaksi (Anugrah, 2019)

\section{Kesulitan Memecahkan Masalah Numerik}

Sebagian besar siswa masih kesulitan dalam menyelesaikan soal yang diberikan oleh guru. Dalam mengerjakkan soal stoikiometri siswa belum menggunakan kemampuan analisis secara maksimal (Kristiyanto, 2018). Menurut Shadreck dan Enunuwe (2018) kesulitan siswa kimia dalam memahami dan memecahkan soal-soal stoikiometri adalah kurangnya pemahaman konsep mol, ketidakmampuan menyetarakan persamaan kimia, penggunaan hubungan stoikiometri yang tidak konsisten, mengidentifikasi pereaksi pembatas, penentuan hasil teoritis, dan identifikasi zat yang berlebihan. Siswa masih kesulitan menjawab soal-soal algoritmik dikarenakan pada soal-soal algoritmik, siswa tidak hanya memerlukan keterampilan matematis, tetapi juga diperlukan analisis soal, perencanaan penyelesaian soal sesuai dengan konsep, dan pemahaman soal. Kelemahan pemecahan masalah yang terjadi pada siswa disebabkan oleh kesalahan memahami masalah, transformasi, komputasi, penyimpulan jawaban dan keterbatasan kemampuan siswa dalam matematika (Suhardil Andi, dkk., 2020).

\section{Gagasan Mengatasi Kesulitan Belajar Siswa dalam Topik Stoikiometri}

Guru berperan penting memberikan penguatan (internalisasi) terhadap siswa untuk mengokohkan konsepsi barunya. Diketahui bahwa beberapa penelitian menemukan miskonsepsi siswa diakibatkan dari kesalah pahaman konsep dan tidak dapat membedakan antara atom, molekul, ion. Maka dari itu, remediasi pembelajaran diperlukan untuk merubah pra-konsepsi, pemahaman konsep prasyarat, mengetahui hasil belajar siswa yang akan dianalisis tahap-tahap pemecahan masalahnya sehingga dapat didentifikasi kesulitan yang dialami oleh siswa tersebut. Konsep prasyarat pada materi stoikiometri yaitu tata nama senyawa, persamaan reaksi, dan konsep mol. Secara sederhana, untuk mengatasi miskonsepsi siswa yang masih sulit membedakan antara atom, molekul dan ion bisa memanfaatkan bentuk visualisasi dan kemudian dijelaskan oleh guru, sebagai referensi ditunjukkan gambar 1.

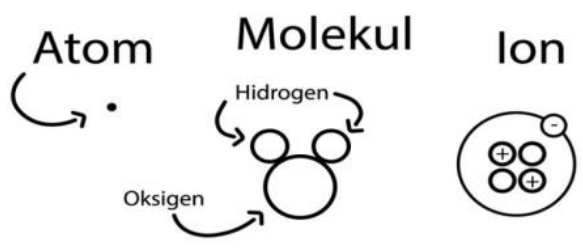

Gambar 1. Visualisasi video atom, molekul dan ion

Miskonsepsi lain yaitu anggapan bahwa seluruh reaktan habis bereaksi, padahal terdapat reaktan yang habis terlebih dahulu sehingga membatasi reaksi tersebut (terdapat pereaksi pembatas), 
hal tersebut dapat diatasi dengan menggunakan ilustrasi dan analogi yang relevan dan menarik perhatian siswa. Misalnya ketika akan membahas tentang konsep mol, guru dapat mengaitkan tentang bagaimana cara membuat kue, diperlukan sejumlah bahan, dan pada praktiknya terdapat kelebihan, maka siswa diharapkan mampu mengaitkannya dengan konsep pereaksi pembatas. Sebagaimana visualisasi itu penting, dengan pemanfaatan PhET juga dapat menjadi sarana untuk mengatasi miskonsepsi tersebut, adapun simulasinya dapat diakses melalui https://phet.colorado.edu/in/simulations/reactants-products-and-leftovers

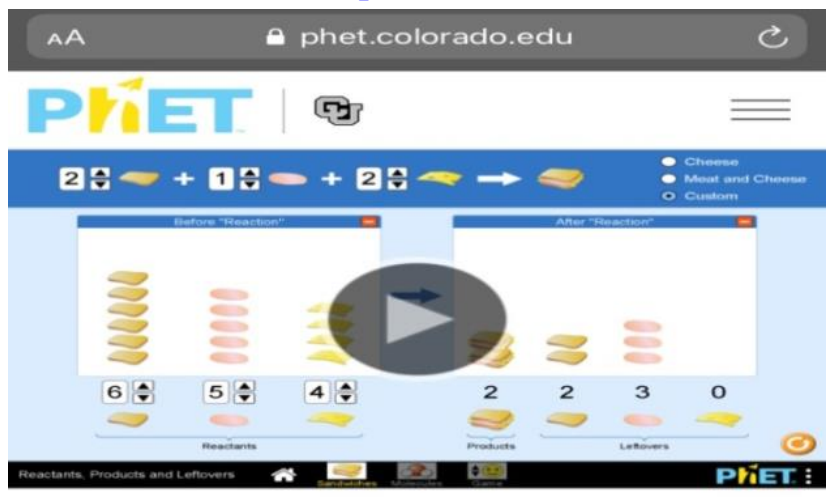

Gambar 2. Tampilan simulasi PhET untuk reaktan, produk dan reaktan pembatas

Selain itu, kejelasan dalam memaparkan materi tentang suatu konsep sangat berperan penting, seperti miskonsepsi yang dialami siswa mengenai suatu persamaan reaksi, yang disetarakan adalah jumlah koefisiennya. Sebagaimana diketahui, dalam menyetarakan jumlah atom digunakan pemberian koefisien reaksi di depan zat-zat yang bereaksi. Misalnya pemaparan yang kurang tepat seperti penggunaan bahasa "setarakan koefisiennya" dapat memunculkan anggapan yang salah padahal yang dimaksud adalah "setarakan jumlah atomnya dengan menambahkan angka koefisien".

Kurangnya pemahaman terhadap sejumlah konsep mempengaruhi kemampuan untuk menyelesaikan masalah stoikiometri, diantaranya pemahaman konseptual hukum dasar kimia, konsep stoikiometri dasar seperti konsep mol, menyetarakan persamaan kimia, mengidentifikasi pereaksi pembatas. Maka dari itu, pendidik kimia harus memastikan bahwa siswa perlu memahami konsepkonsep ini sebelum dapat memecahkan masalah numerik kuantitatif. Model pembelajaran yang digunakan oleh guru pada saat menyampaikan materi, termasuk salah satu faktor yang memengaruhi kesulitan belajar siswa, maka dari itu kompetensi pedagogik guru dalam pengelolaan pembelajaran sangat diperlukan. Pendidik kimia harus menerapkan teknik pedagogis pemecahan masalah (problem solving) sebagai sarana untuk mengatasi kesulitan siswa dalam stoikiometri, mengkondisikan siswa untuk menemukan (to discover) konsep-konsep serta memberikan kesempatan dalam pembelajaran untuk berdiskusi antar teman (peer-discussion) mengenai makna-makna konsep masing-masing siswa, sehingga mampu bertukar fikiran.

Peta konsep juga merupakan bagian penting yang diperlukan untuk mengungkap hubungan antar konsep dan menekankan gagasan pokok yang disusun secara hirarkis dan jelas. Peta konsep tersebut terdiri dari hukum-hukum dasar kimia yang meliputi Hukum Lavoiser, Hukum Proust), Hukum Dalton, Hukum Gay Lussac dan Hukum Avogadro, dimana banyak ditemukan miskonsepsi pada bagian ini. Selanjutnya dalam konsep mol, meliputi konversi jumlah mol dengan jumlah partikel, massa dan volume zat, penentuan rumus empiris dan molekul, penentuan kadar zat dalam suatu senyawa, penentuan pereaksi pembatas, banyaknya zat pereaksi dan hasil reaksi. Hal tersebut memudahkan siswa untuk mengingat konsep mol yang sering menimbulkan kesalahan dan miskonsepsi dalam memahami stoikiometri. Adapun contohnya adalah sebagai berikut: 


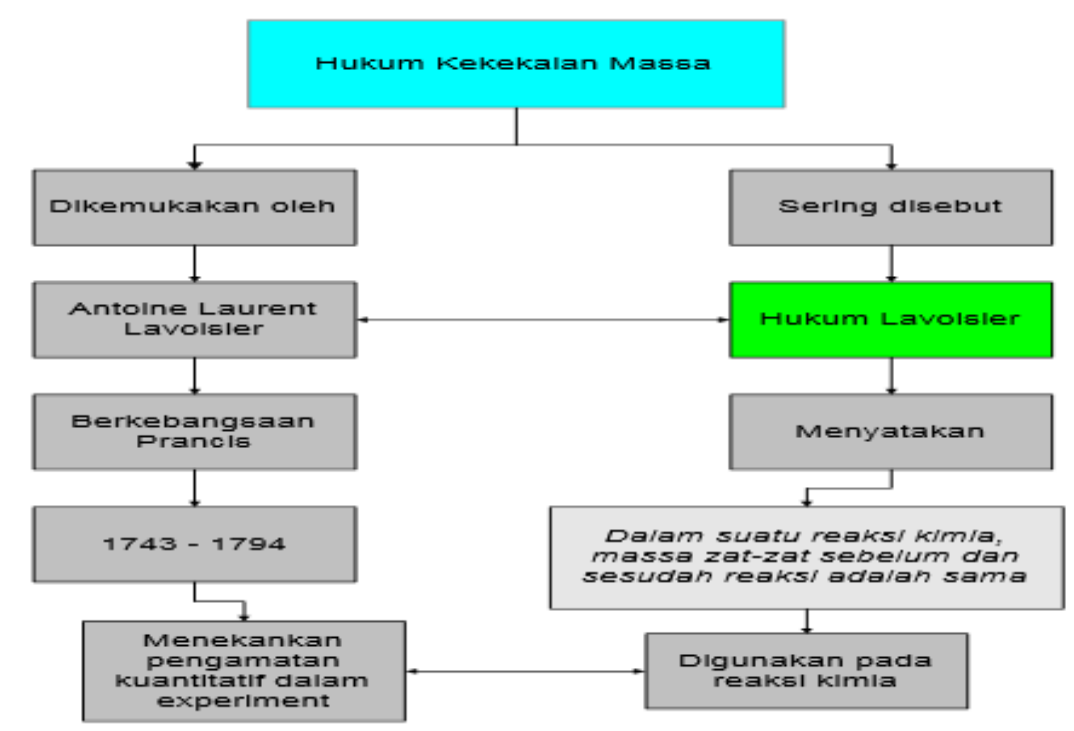

Gambar 3. Peta konsep Hukum Kekekalan Massa (Hukum Lavoisier)

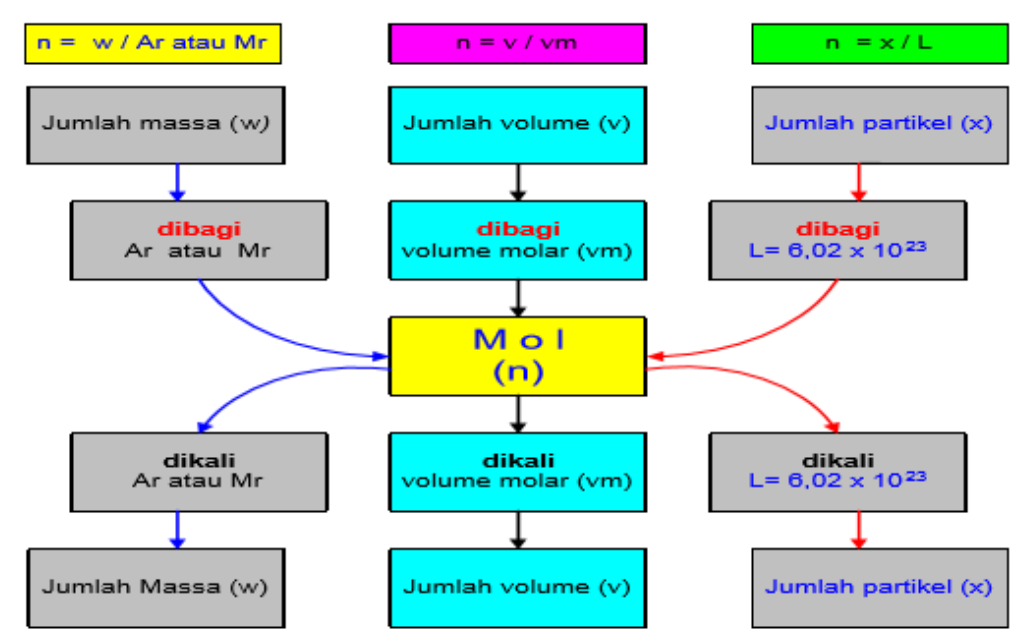

Gambar 4. Peta konsep hubungan jumlah mol (n) dengan jumlah partikel (x), jumlah massa (w), dan jumlah vulume (v) suatu zat

Disisi lain, soal-soal algoritmik pada stoikiometri biasanya lebih banyak diujikan dibandingkan soal konseptualnya. Upaya memperbaiki kesalahan konsep materi kimia yang dialami siswa dapat dilakukan melalui pembelajaran dengan menggunakan teknik mencatat mind map. Mind map dapat membantu merangsang pengungkapan pikiran dengan meringkas materi dari setiap sub bab pokok bahasan yang mana dalam materi stoikiometri ini dapat dituangkan berupa hukum-hukum kimia yang mendukung stoikiometri dan dilibatkan pada perhitungan, serta variabel-variabel yang terlibat dalam setiap perhitungan stoikiometri.

Dalam memecahkan masalah numerik stoikiometri kimia, setiap siswa memiliki cara, proses dan gaya berpikir yang berbeda-beda. Terutama siswa yang memiliki gaya kognitif field dependent (mempunyai kecenderungan bergantung oleh lingkungan dan juga mudah terpengaruh oleh lingkungannya) sejalan dengan penelitian Ipilo, dkk., (2018), maka dalam memecahkan masalah numerik, langkah yang dapat dilakukan yaitu mengarahkan siswa untuk membiasakan mengerjakan soal dengan menggunakan langkah penyelesaian problem solving, sesuai dengan tahapan Malters dalam dalam Kristiyanto (2018): analisis soal, perencanaan soal (memecahkan rumus standar, menganalisis hubungan antar konsep, 
dan membuat transformasi), melakukan perhitungan, dan tahap pengecekan jawaban. Dengan demikian, mampu menghindari jalan pintas dalam menyelesaikan soal, mengenal titik kesulitan pada soal, membiasakan untuk menyematkan simbol, persamaan, dan notasi, serta melatih ketelitian menjawab soal. Karena hal yang menjadi kesalahan dalam perhitungan yaitu siswa tidak melibatkan satuan atau simbol suatu zat, maka pendidik harus mengenalkan teknik analisis dimensi perhitungan stoikiometri, yaitu suatu cara sistematik pemecahan masalah numerik dalam kimia dengan selalu mengikutsertakan satuan untuk besaran yang dihitung sehingga apabila ada suatu kesalahan dalam menjawab, akan segera menyadari kesalahan tersebut dengan bantuan satuan yang dihasilkan dari perhitungan. Hal ini ditunjukan oleh miskonsepsi siswa terhadap $\mathrm{Ar}$ dan $\mathrm{Mr}$ memiliki satuan yang merupakan kesalahan umum dalam penyelesaian soal numerik padahal yang memiliki satuan adalah Massa molar. Contoh soal dengan langkah penyelesaian masalah adalah: "Sebanyak 10 gram padatan kalium klorat dipanaskan dalam wadah tertutup, sehingga terjadi reaksi sesuai persamaan: $2 \mathrm{KClO}_{3(\mathrm{~s})} \rightarrow 2 \mathrm{KCl}_{(\mathrm{s})}+3 \mathrm{O}_{2(\mathrm{~g})}$. Maka massa zat dalam wadah setelah reaksi selesai adalah...”

\section{- Analisis}

Diketahui : a) Massa padatan $\mathrm{KClO}_{3}=10$ gram ; b) Koefisien senyawa $\mathrm{KClO}_{3}$ sama dengan $\mathrm{KCl}$ dan perbandingan koefisien $\mathrm{KClO}_{3}$ dengan $\mathrm{O}_{2}$ adalah 2:3

Ditanyakan : massa zat dalam wadah reaksi setelah selesai

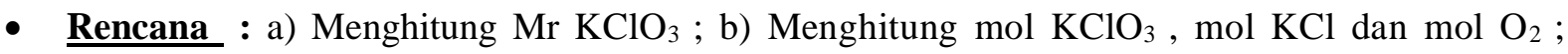
c)Menghitung massa $\mathrm{KClO}_{3}$ dan massa $\mathrm{O}_{2}$; d)Menghitung massa zat setelah reaksi

\section{- Perhitungan}

$\mathrm{Mr} \mathrm{KClO}_{3}=(30+35,5+48) \mathrm{gram} / \mathrm{mol}=113,5$

$>\mathrm{Mol} \mathrm{KClO}_{3}=10$ gram $/ 113,5$ gram $=0,082 \mathrm{~mol}$

$\mathrm{Mol} \mathrm{KCl}=\mathrm{Mol} \mathrm{KClO}_{3}=0,082 \mathrm{~mol}$

$\mathrm{Mol} \mathrm{O}_{2}=3 / 2 \times \mathrm{mol} \mathrm{KClO}_{3}=0,123 \mathrm{~mol}$

Massa $\mathrm{KCl}=0,082 \mathrm{~mol} \times(39+25,5) \mathrm{gram} / \mathrm{mol}=6,109$ gram

Massa $\mathrm{O}_{2}=0,123 \mathrm{~mol} \times(2 \times 16) \mathrm{gram} / \mathrm{mol}=3,936 \mathrm{gram}$

Massa setelah reaksi $=$ massa $\mathrm{KCl}+$ massa $\mathrm{O}_{2}=10$ gram

- Evaluasi maka jawabannya yaitu sama dengan 10 gram (Proses dalam ruangan tertutup maka berlaku Hukum Lavoiser dimana massa zat sebelum dan sesudah bereaksi adalah sama)

Mngetahui apakah siswa masih memiliki miskonsepsi dan memiliki kesulitan dalam materi stoikiometri merupakan hal yang penting. Apabila masih terdapat miskonsepsi dan pemahaman siswa yang masih rendah terhadap materi stoikiometri, maka pembelajaran remidi dapat dilakukan dengan harapan mencapai tingkat ketuntasan dalam mengatasi kesulitan belajar siswa. Keberhasilan siswa dalam memahami konsep-konsep materi stoikometri menjadi faktor penentu dalam mempelajari materi kimia selanjutnya yang memerlukan konsep stoikiometri sebagai materi prasyaratnya, seperti Termokimia dan Kesetimbangan Kimia. Pembelajaran remidi yang bermakna perlu dilakukan dengan bantuan suatu stategi yang tepat, salah satunya adalah pembelajaran remidi dengan metode pemecahan masalah seperti dengan langkah Polya yang didominasi oleh aktivitas siswa dan tutor sebaya meliputi kegiatan focus group discussion, tanya jawab antar teman, permainan (games) dan presentasi

\section{Simpulan}

Kesulitan belajar dan miskonsepsi siswa disebabkan oleh beberap faktor diantaranya cara mengajar guru menggunakan model pembelajaran konvensional, kurangnya minat siswa dalam mempelajari kimia dan kurangnya usaha siswa untuk mengumpulkan data saat proses pembelajaran 
berlangsung. Kompetensi pedagogik guru sebagai pendidik memiliki peran yang penting dalam kegiatan belajar mengajar. Pendidik perlu menganalisis dan memahami kesulitan siswa juga menerapkan teknik pedagogis pemecahan masalah sebagai sarana untuk mengatasi kesulitan siswa dalam pemecahan masalah stoikiometri yang menerapkan banyak perhitungan matematis salah satunya dengan selalu mengajarkan langkah- langkah pemecahan masalah yang benar didalam penyelesaian soal. Langkah Polya merupakan salah satu alternatif untuk mengetahui kesalahan-kesalahan yang dilakukan siswa dalam mengerjakan soal. Konsep stoikiometri digunakan pada materi kimia lainnya seperti termokimia, kesetimbangan kimia dll, maka dari itu perlu mencapai tingkat ketuntasan dalam mengatasi kesulitan belajar siswa melalui pembelajaran remidi.

\section{Referensi}

Aini, R.G., Ibnu, S., \& Budiasih, E. (2017). Identifikasi Miskonsepsi dalam Materi Stoikiometri pada Siswa Kelas X di SMAN 1 Malang Melalui Soal Diagnostik Three-Tier. J-PEK (Jurnal Pembelajaran Kimia), 1(2), 50-56.

Anugrah, I.R. (2019). Telaah Topik Stoikiometri Sma: Miskonsepsi Dan Strategi Pembelajarannya. Jurnal Pendidikan Kimia, 3(2), 94-103.

Astuti, P., Redjeki, T., \& Nurhayati, T.N.D. (2016). Identifikasi miskonsepsi dan penyebabnya pada siswa kelas XI MIA SMA Negeri 1 Sukoharjo tahun pelajaran 2015/2016 pada materi pokok stoikiometri. Jurnal Pendidikan Kimia, 5(2), 10-17.

Chang, R. (2010). Chemistry 10th edition. New York: McGraw-Hill.

Damayanti, E.T. (2017). Analisis miskonsepsi pesertadidik dengan menggunakan metode certainty of response index (CRI) termodifikasi pada konsep stoikiometri di SMA Negeri 5 Semarang. Thesis, Universitas Islam Negeri Walisongo.

Ipilo, S.R., Sihaloho, M., \& Paputungan, M. (2018). Deskripsi Metakognitif Siswa Yang Memiliki Gaya Kognitif Field Dependent Dalam Memecahkan Masalah Stoikiometri. Jurnal Entropi, 13(2), 221-234.

Kristiyanto, S., Yamtinah, S., \& Saputro, S. (2018). Analisis Langkah-Langkah Penyelesaian Soal Model Testlet Pada Materi Stoikiometri. Jurnal Penelitian Pendidikan Pendagogia, 21(2), 132-141.

Lestari, E.A., Harjito., Susilaningsih, E., \& Wijayati, N. (2021). Analisis Miskonsepsi Menggunakan Tes Diagnosa Three-Tier Multiple Choice Pada Materi Stoikiometri. Jurnal Inovasi Pendidikan Kimia, 15(2), $2824-2830$.

Noorarniea, A.M., Supardi, K.I., Sumarni, W., \& Karnawan. (2019). Analisis Kesalahan Siswa Dalam Mengerjakan Soal Stoikiometri Melalui Langkah Polya, Jurnal Inovasi Pendidikan Kimia, 13(2), 2414-2424.

Setyorini, A.D., Saputro, A.N.C., \& Haryono (2018). Penerapan Model Pembelajaran Problem Solving Disertai Kartu Soal Untuk Meningkatkan Kemampuan Analisis Dan Prestasi Belajar Siswa Pada Materi Stoikiometri Di Kelas X Mipa 2 Semester Genap SMA Batik 1 Surakarta. Jurnal Pendidikan Kimia, 7(2), 267-274.

Shadreck, M., \& Enunuwe, O.C. (2017). Problem Solving Instruction for Overcoming Students Difficulties in Stoichiometric Problems. International Journal of Acta Didactica Napocensia, 10(4), 69-78. 
Shui-Te, L., Kusuma, I.W., Wardani, S., \& Harjito. (2018). Hasil Identifikasi Miskonsepsi Siswa Ditinjau dari Aspek Makroskopis, Mikroskopis dan Simbolik (MMS) pada Pokok Bahasan Partikulat Sifat Materi di Taiwan. Jurnal Inovasi Pendidikan Kimia, 12(1), 2019-2030.

Sidauruk, S. (2005). Miskonsepsi stoikiometri pada siswa SMA. Jurnal Penelitian dan Evaluasi Pendidikan, VII(2), 253-272.

Suhardi, A., Susanti, L.Y., \& Susilawati. (2020). Pengaruh Penggunaan Mind Map terhadap Pemahaman Konsep Stoikiometri. Journal of Natural Science and Integration, 3(1), 106-114.

Winarni, S., Ismayani, A., \& Fitriani. (2013). Kesalahan Konsep Materi Stoikiometri yang Dialami Siswa SMA. Jurnal Ilmiah Didaktika, 14(1), 43-59.

Zakiyah., Ibnu, S., \& Subandi. (2018). Analisis Dampak Kesulitan Siswa Pada Materi Stoikiometri Terhadap Hasil Belajar Termokimia. EduChemia Jurnal Kimia dan Pendidikan, 3(1), 119-134.

Zamania, I.Z. (2008). Upaya Peningkatan Kompetensi Pedagogik Guru Dalam Proses Belajar Mengajar Di Raudhatul Athfal Al-Ikhlas Sukoda. Skripsi, UIN Malang. 